\title{
TQLM Total Quality Leaders Manufacturing
}

\author{
Alnamer M. Abdulkhalaq \\ Master Student (IS) \\ Department of Faculty of \\ Computing and Information \\ Technology \\ King Abdulaziz University, \\ Saudi Arabia
}

\author{
Fayez N. Al Sehani \\ Master Student (IS) \\ Department of Faculty of \\ Computing and Information \\ Technology \\ King Abdulaziz University, \\ Saudi Arabia
}

\author{
Syed Hamid Hasan \\ Professor \\ Department of Faculty of Computing and \\ Information Technology \\ King Abdulaziz University, \\ Saudi Arabia
}

\author{
Abdullah H. Bin Sawad \\ Master Student (IS) \\ Department of Faculty of \\ Computing and Information \\ Technology \\ King Abdulaziz University, \\ Saudi Arabia
}

\begin{abstract}
Success can never be achieved without a wise leader who has mastered leadership arts to orchestrate all available resources (people, funds, knowledge, techniques and tools) into the correct path. On other hand, Total Quality Management (TQM) philosophy has emerged and was seen by Governments, Organizations and Firms (GOFs) as way to increase products/services quality from acquiring raw materials up to the output final shape. TQM principles are extremely powerful to be applied in all GOFs aspects and business units. Therefore, GOFs start adopting TQM in each and every part beginning with the most important part of the chain which is the leadership. In contrast, GOFs were facing issues in finding out, recruiting or promoting people with leadership aura. Whereas, there are many employees within their entities who have the initials to be successful leaders, but unfortunately their talents are hidden and they never get a chance to liberate and show their endowment. This paper is proposing a process that will help GOFs to explore, build and manufacture high quality leaders. This process is named as Total Quality Leaders Manufacturing (TQLM). It consists of the following steps: Candidates Selecting, Candidates Preparing, Overall Business Understanding, Culture Understanding, Leadership Knowledge Gaining, BestFit Position Finding and Continuous Leader Improving.
\end{abstract}

\section{Keywords}

Total Quality Management; Leadership; Leaders; Manufacturing;

\section{INTRODUCTION}

Leadership is the process of formulating GOFs visions, missions, goals and strategies and then the ability of making individuals to do all the things required to achieve those defined goals with love, passion, loyalty and commitment. Moreover, leadership is also to make a change in society culture, people thinking and way of doing things. There are two basic types of leadership transformational and transactional. Simply, transactional leadership puts more concentration on the processes and way of achieving them. On the contrary, transformational leadership cares more about the human and his/her needs to make him/her more comfortable to achieve the process in more efficient and effective way.
In late 1970s, the concept of TQM has emerged. TQM principle is the focus on enhancing products/services value chains activities to reach customer satisfaction via scientific analysis and quantitative measures. In recent years, TQM has interfered positively in all aspects of GOFs businesses. As a result, a new concept called Total Quality Leadership (TQL) is a management methodology that concentrates in delivering top customer value throughout obtaining excellence in parts of GOFs that contribute in delivering that value [1]. TQL principle is standing upon three strong pillars employee involvement, customer satisfaction and continuous improvement [1]. Thus, leaders nowadays are seen as TQM leaders who have the ability of accomplishing goals with total quality that exceeds the expectations of customers.

Total Quality Leaders who have wise leadership capabilities are always representing the key success factor and the driver towards excellence for (GOFs). In general, most of these leaders share some common characteristics charisma, creativity, responsibility, innovation, coaching, visionary, customer focus, knowledge, communication skills, integrity and commitment, as in $[1,3,5,9,10]$. Such leaders who own all these attributes are extremely hard to find. As it is well known, some of those characteristics are considered as congenital and others are acquirable. Therefore, GOFs should somehow have a way WHICH allows them to explore and discover those employees who have the initials of leadership talents. The authors of this paper have utilized their knowledge and experiences in the market to formulate a process that helps GOFs in discovering and preparing total quality leaders.

This paper is structured as follows. Section 2, is an overview and comparison of the literature review referenced. Section 3 , gives a summary of the fundamentals TQM. Section 4, discusses the main concepts of Leadership and Leaders characteristics. Section 5, addresses the research problem that we are trying to solve. Section 6, explains the proposed solution of the paper's problem. Finally, a conclusion that summarizes the paper is mentioned in section 7 .

\section{LITERATURE REVIEW}

In [1], R. S. Ulle and A. N. Kumar introduced a new leadership theory in compliance with TQM principles. The theory is stated that TQM leaders should change GOFs culture 
to be customer oriented. Also, assure the delivery of customer value as promised; achieve high performance via formulating robust long-term strategies. They should apply a well taking care approach of employees' needs and ambitions. Furthermore, they should play the role of good example that employees may get inspired by in terms of the way they treat people, loyalty and commitment.

In [2], an empirical study, of manufacturing companies certified by ISO, has been conducted to assess the interrelationship between leadership behavior and TQM excellence. The study proves that the behavior of leadership has high positive impact on TQM excellence.

In [3], the study focused on quality leadership communication. It has mentioned that there are many physical and physiological barriers that may prevent a leader to be a quality communicator. For example, barriers like culture, noise, introspection, perception, message/vague message, environment and stress might have significant effects on the communication process. The authors have suggested that a communication framework should be designed to break all those barriers as much as possible.

The authors of [4] have conducted a real life case in Saudi Arabia public hospitals to find out the effects of the two basic styles of leadership. Those styles are transformational and transactional leadership. Thus, transactional leaders showed negative effects in achieving TQM. On the other hand, transformational leaders showed high positive impact on TQM.

As in [5], young and less experienced employees are more likely to implement TQM philosophy if their leaders have more integrity and commitment.

In [6], the authors have reviewed how top management commitment is affecting TQM? They came up with a result which stated that top management commitment is a preliminary point for TQM implementation and practicing. Moreover, they have suggested a conceptual framework model to visualize their outcomes. Simply, the model emphasizes that customer orientation, customer satisfaction; organization performance, service quality excellent maintenance and market orientation are key inputs for having successful TQM implementation. But all those inputs are directly affected by top management commitment.

In [7], the study has shown that transformational leadership is impacting TQM practices with $6 \%-17 \%$ of organization culture change.

In [8], the authors have taken on their shoulders the burden of comparing e-learning TQM framework with academic kikpatrick models-applying TQM. They have resulted into four principles that guarantee having new assessment models. Those four principles are synergistic relationships, selfevaluation \& continuous improvement, no human-human evaluation and top management success responsibility.

In [9], the authors have conducted a comparative study between two basic types of leadership (transformational versus transactional). They have highlighted the essential characteristics of leaders of each type. More details are covered in section IV.

In [10], a proof has been made that knowledge management (KM) and TQM are tightly coupled in cost reduction and quality improvement respectively. Thus, leaders must have well knowledge in regards to KM \& TQM philosophies.

\section{TOTAL QUALITY MANAGEMENT}

The main objective of TQM, that it can provide business growth through a clear roadmap. This roadmap starts with a clear vision of the importance of customer satisfaction. Then, having quality leaders characterized by total quality leadership attribute, who care a lot about delivering quality value to customers. After that, processes will be directly affected in respect to employees' involvements and inputs because they are the ones who deal with things in daily basis and know better the weaknesses and strengths. Hence, partners are also influenced by all these as TQM changes/enhancements to the work activities will change the levels of quality and measures of accepting and inspecting their supplies. Lastly, it is important to realize that continuous improvement is an essential for sustaining business growth.

\section{TOTAL QUALITY LEADERSHIP \& LEADERS}

As mentioned earlier, there are two basic types of leadership:

- Transformational: is the harmonization between leaders and followers in a way that all of them are collaborating together with high level of loyalty, passion and sincerity. This type of leadership makes more awareness to do the tasks in efficient and effective way. Also, it is an Inspirational strategy in order to focus on organizational goals.

- Transactional: is a boss whose job is only giving orders to his/her followers. There is no participation and cooperation in achieving activities hand to hand with followers. There is only one arbitrary opinion and there is a limited space for others to share their thoughts freely.

Another key point, characteristics like respect, charisma, creativity, team spirit, coaching and responsibility are common attributes of transformational leaders. Consequently, TQM leadership is derived from the transformational leadership with a slight difference that TQM leadership is putting more focus on the customers and their needs. In general, TQM leaders are taking care of three things:

- Employee: securing their needs, encouraging them, listening to their opinions and building their skills, capabilities and knowledge.

- Customer: understanding their needs and working hard to satisfy them.

- Continuous improvement: for business processes and activities to reach producing high quality products/services in effective costing, timing and resources.

\section{RESEARCH PROBLEM}

GOFs are suffering scarcity in finding out good leaders who can drive the institution towards excellence and success. On the other hand, many employees have leadership capabilities such as knowledge, charisma, goodness, critical thinking, strictness, understanding, awareness, strategic analysis, future visioning etc. They have some of these inside themselves, but no one gave them the opportunity to prove themselves and unleash their talents. Therefore, many of them tend to leave the institution especially if their efforts are not appreciated. Thus, finding out any way to discover such leaders within the GOFs entities, would be this research paper's concern. Hence, the research question that is taken up in this paper is as follows: 


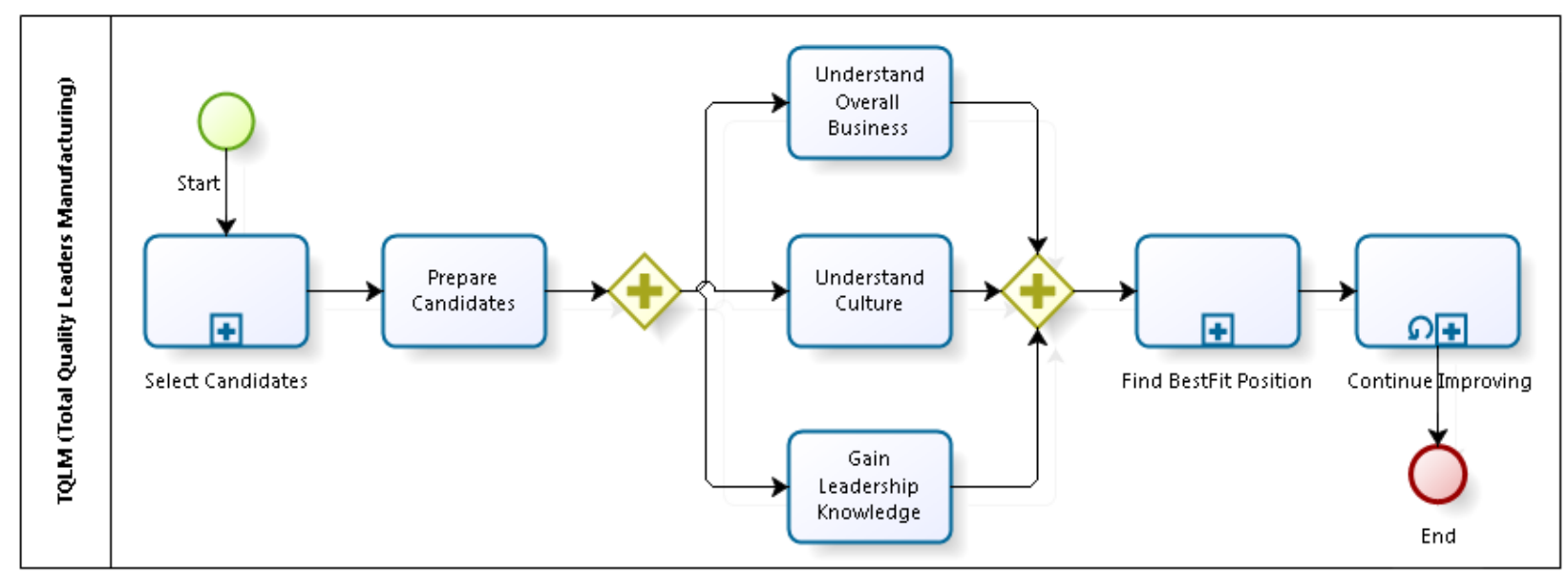

Figure 1: TQLM Process

Q: "Is there a well-defined process that can help in discovering and producing high quality leaders?"

\section{PROPOSED SOLUTION}

There is a strong trend by GOFs to apply TQM principles in all aspects of the institution and this starts with leadership. To accomplish such objective it is essential for them to find out the shoulders who will carry out all necessary actions and direct the institution toward success with their leadership capabilities. Based in that, the proposed solution is to introduce a new concept named Total Quality Leaders Manufacturing and abbreviated as TQLM. The main idea is that we will develop a process that is derived from TQM philosophies. It will help and guide GOFs to manufacture quality leaders within their own entities. The main objectives of this concept is to enable GOFs to produce total quality leaders through encouragement, motivation and giving every one interested a chance to be a good leader with high quality. TQLM process consists of seven steps as shown in the figure 1. It is drawn using BPMN 2.0 Business Process Modeling Notation using BizAgi Tool.

TQLM process can be elaborated as follows:

Step 1: Candidates Selecting: this is a complex activity which means it consists of sub-activities as marked with small + sign in figure 1 and its details is shown in figure 2. But as a starting point, an announcement has to be made for adopting TQLM process in the institution for receiving candidates' applications and CVs. First sub-activity is to interview the candidates and collect as much information as possible about them and examine their initials to be leaders. Second subactivity is to start filtering the list through assessing their leadership initial characteristics which include early wakingup, eager of continuous learning, patience, good attitude, charisma, improvisation \& speaking, organized and systematic. Last sub-activity is to nominate and approve the potential leaders' final list.

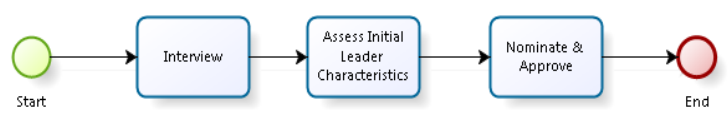

Figure 2: Select candidates step

Step 2: Candidates Preparing: this is just to prepare the potential leaders and introduce them to TQLM process. They should know the roadmap of TQLM and what they are going to go through in the upcoming period and what is required from them in each further steps.

Step 3 + Step 4 + Step 5: these are considered as the core idea behind TQLM process and they can start in parallel manner. They can be defined as follows:

- Overall Business Understanding: this step is to give the potential leaders deep and intensive understanding of each and every aspect about the institution including structures, administration instructions and policies. Each potential leader must work in all business units (department \& divisions). They are supposed to work for at least six months period in core business units and at least three months period in other supporting business units. This will facilitate understanding different angles, perspectives and concerns of each business unit for any idea to be adopted in the future. Moreover, it will help them in achieving the strongest value of a leader which is relationship building. Also, they will know how the business units are interlinked and cooperate together in a more comprehensive way.

- Culture understanding: potential leaders are supposed to understand both local and global culture of institution's people and business. They should concentrate in gathering information regarding peoples behaviors, needs, requirements, and things that motivate them to work with passion and love. Also, they should collect information concerning business markets locally and globally. 
This is extremely important for leaders in the time of planning and designing products/services strategically. In addition, this will help them in assessing in advance the success ratio of any program they intend to apply.

- Leadership Knowledge Gaining: some investments should be made for potential leaders in order to gain leadership knowledge through professional courses and certifications. They should focus in building their capabilities in solving problems, leading people, appreciating peoples' differences \& psyches, human development, future visionary, strategic planning, critical thinking, change management, quality management, achieving results, project management, technology and information system.

It is important to know that these three steps will require regular reporting and evaluation of the potential leaders' progress and achievements. Excluding of potential leaders in case of unacceptable progress may be considered.

Step 6: BestFit Position Finding: this step should start for each potential leader after he/she finishes the three previous steps. In general, this will evaluate the potential leaders' outcomes, interests, visions and strategic plans or programs. After that, things will be explored and bestfit positions for each leader will be clearly obvious. Some of them will be more suitable for specific business unit or for the overall institution. Figure 3 shows the three sub-activities of this complex step. First sub-activity is to explore interests \& visions. After going through all core steps the potential leaders must have their own visions, interests and plans. They have to present them and elaborate their views. Second subactivity is to evaluate all the potential leaders' results and decide their bestfit positions. At last, approve the bestfit positions from the top management.

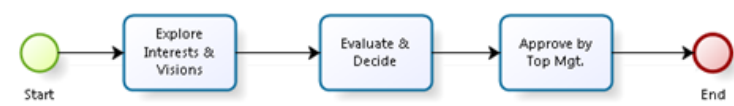

\section{Figure 3: Find BestFit position step}

Step 7: Continuous Leader Improving: proceeding from the saying "Nothing is Perfect", continuous improvements for leaders should be applied. This is also a complex and looping step as shown in figure 4. First sub-activity is to assess and identify leaders' weaknesses and strengths. Then, start filling the gaps throughout strengthening their weaknesses and reinforcing their strengths.

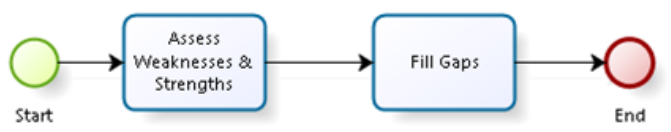

Figure 4: Continue leader improving

\section{CONCLUSION AND FUTURE WORK}

Doing things by following a series of pre-defined steps is easy and doable by many people. Whereas, having the art of formulating these steps from scratch in efficient and effective manner supported with evidences proves the essentiality of each and every step is what leadership is all about. In addition, providing intensive care for employees, customers and partners in all fine details throughout inspiring, listening, appreciating and turning dreams into facts is the hardest part for being a leader. In contrast, GOFs have their own ways for manufacturing products/services. But they face difficulties in finding out good leaders who will make a change in the institutions culture, ways of doing things or dealing with problems and solving them. This paper is introducing a new way that is going to help in discovering quality leaders within their entities and enriching their talents of leading people. The process is named as TQLM total Quality leaders manufacturing and it contains seven essential steps: Candidates Selection, Candidates Preparation, Overall Business Understanding, Cultural Understanding, Leadership Knowledge Gaining, BestFit Position Finding and Continuous Leadership Improvement. A practical experiment to test the effectiveness and efficiency of this process is highly recommended as future work.

\section{ACKNOWLEDGMENTS}

Our thanks to professor Syed for his assistance in this research from his long experience in Total Quality Management (TQM).

\section{REFERENCES}

[1] R. S. Ulle and A. S. Kumar, "A Review on Total Quality Leadership in TQM Practices-Industrial Management and Organizations", International Journal of Emerging Research in Management \& Technology, vol.3, issue: 5, May 2014

[2] W. R. Wickramaratne, "Leadership and TQM Excellence: Empirical Study of ISO Certified Manufacturing Firms in Sri Lanka," International Journal of Arts and Commerce, vol. 2, no. 9, 2013.

[3] S. Arsovski and S. jan Nikezić, "Leadership communications and quality," in 5th International, 2012.

[4] M. Alharbi and R. Z. Yusoff, "Leadership styles, and their relationship with quality management practices in public hospitals in Saudi Arabia," Management, vol. 1, no. 10, pp. 59-67, 2012.

[5] K. Ismail, W. Khurram, and S. K. A. Jafri, "Role of leaders' behavioral integrity in determining successful TQM implementation and organizational performance: A study on public hospitals of Pakistan," International Journal of Humanities and Social Science, vol. 1, no. 10, pp. 236-241, 2011.

[6] E. Mustafa and A. T. Bon, "Role of top management leadership and commitment in total quality management in service organization in Malaysia: a review and conceptual framework," Elixir Human Resource Management, vol. 51, pp. 11029-11033, 2012.

[7] H. A. A. Argia and A. Ismail, "The Influence of Transformational Leadership on the Level of TQM Implementation in the Higher Education Sector," Higher Education Studies, vol. 3, no. 1, Jan. 2013. 
[8] O. Ibrahim, "Total Quality management (TQM) and Continuous Improvement as Addressed by Researchers," International Journal of Scientific and Research Publications, p. 458

[9] K. J. Ekuma, "Transformational Leadership: Implications for Organizational Competitive Advantage," International Journal of Human Resource Studies, vol. 4, no. 1, p. 276, May 2014.
[10] A. A. Ashraf, S. A. Lodhi and U. Farooq, "An Investigation of Leadership-Culture Fit with Quality Improvement andCost Reduction by Synchronizing TQM and KM Philosophies", World Applied Sciences Journal, vol. 32, no. 3, p. 478-491, 2014

[11] Nvr Naidu, Km Babu \& G.Rajendra (2007), Total Quality Management, NewAge Internationals, New Delhi 